\title{
RESEARCH
}

Open Access

\section{Vitamin C may reduce the duration of mechanical ventilation in critically ill patients: a meta-regression analysis}

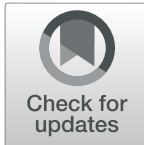

Harri Hemilä ${ }^{*}$ (D) and Elizabeth Chalker ${ }^{2}$

\begin{abstract}
Background: Our recent meta-analysis indicated that vitamin C may shorten the length of ICU stay and the duration of mechanical ventilation. Here we analyze modification of the vitamin C effect on ventilation time, by the control group ventilation time (which we used as a proxy for severity of disease in the patients of each trial).

Methods: We searched MEDLINE, Scopus, and the Cochrane Central Register of Controlled Trials and reference lists of relevant publications. We included controlled trials in which the administration of vitamin $C$ was the only difference between the study groups. We did not limit our search to randomized trials and did not require placebo control. We included all doses and all durations of vitamin C administration. One author extracted study characteristics and outcomes from the trial reports and entered the data in a spreadsheet. Both authors checked the data entered against the original reports. We used meta-regression to examine whether the vitamin $\mathrm{C}$ effect on ventilation time depends on the duration of ventilation in the control group.

Results: We identified nine potentially eligible trials, eight of which were included in the meta-analysis. We pooled the results of the eight trials, including 685 patients in total, and found that vitamin $C$ shortened the length of mechanical ventilation on average by $14 \%(P=0.00001)$. However, there was significant heterogeneity in the effect of vitamin $C$ between the trials. Heterogeneity was fully explained by the ventilation time in the untreated control group. Vitamin C was most beneficial for patients with the longest ventilation, corresponding to the most severely ill patients. In five trials including 471 patients requiring ventilation for over $10 \mathrm{~h}$, a dosage of $1-6 \mathrm{~g} /$ day of vitamin C shortened ventilation time on average by $25 \%(P<0.0001)$.

Conclusions: We found strong evidence that vitamin $C$ shortens the duration of mechanical ventilation, but the magnitude of the effect seems to depend on the duration of ventilation in the untreated control group. The level of baseline illness severity should be considered in further research. Different doses should be compared directly in future trials.
\end{abstract}

Keywords: Antioxidants, Burns, Artificial respiration, Cardiac surgical procedures, Critical care, Dietary supplements, Oxidative stress, Meta-analysis, Sepsis, Systematic review

\footnotetext{
* Correspondence: harri.hemila@helsinki.fi

${ }^{1}$ Department of Public Health, University of Helsinki, POB 41, FI-00014

Helsinki, Finland

Full list of author information is available at the end of the article
}

(c) The Author(s). 2020 Open Access This article is distributed under the terms of the Creative Commons Attribution 4.0 International License (http://creativecommons.org/licenses/by/4.0/), which permits unrestricted use, distribution, and reproduction in any medium, provided you give appropriate credit to the original author(s) and the source, provide a link to the Creative Commons license, and indicate if changes were made. The Creative Commons Public Domain Dedication waiver (http://creativecommons.org/publicdomain/zero/1.0/) applies to the data made available in this article, unless otherwise stated. 


\section{Background}

In controlled trials, vitamin $\mathrm{C}$ has improved endothelial function, lowered blood pressure, increased left ventricular ejection fraction, decreased the incidence of atrial fibrillation, decreased bronchoconstriction, prevented pain, shortened the duration of colds, and decreased the incidence of colds in physically stressed people, and it may also have beneficial effects against pneumonia, see reference [1].

The average person, in good health, maintains normal plasma vitamin $\mathrm{C}$ levels with a daily intake of about 0.1 g/day. However, much higher doses, in the order of grams per day, are needed for critically ill patients to reach normal plasma vitamin $C$ levels [2-5]. Without supplementation, plasma vitamin $\mathrm{C}$ levels are particularly low in critically ill patients [6-10], indicating that the body may have a greater need for vitamin $C$ when under severe stress such as illness requiring intensive care. It seems evident that there are gradual changes in vitamin $\mathrm{C}$ metabolism according to the severity of disease, in that the sicker a patient is, the greater the consumption of vitamin $\mathrm{C}$. This further suggests that the sicker a patient is, the more they are likely to benefit from additional vitamin $\mathrm{C}$.

Given this background, we previously examined whether vitamin $C$ administration has an effect on practical outcomes such as the length of ICU stay, without looking at specific medical conditions. From the results of 12 trials with 1766 patients, we calculated that vitamin $C$ reduced the length of ICU stay on average by $7.8 \%(P<0.001)[1]$.

We also found that in trials in which the control groups were ventilated for $24 \mathrm{~h}$ or more, vitamin C shortened the duration of mechanical ventilation by $18 \%$ $(P=0.001)$ [1]. However, vitamin $\mathrm{C}$ did not have an effect on the duration of mechanical ventilation in trials in which control groups were ventilated for less than 24 h, i.e., trials in patients with less severe illness.
In this study, we hypothesize that there is a continuous relationship between disease severity and the beneficial effect of vitamin $\mathrm{C}$ administration. We used metaregression to analyze the gradual relationship between the effect of vitamin $C$ in the treatment group and the duration of mechanical ventilation in untreated patients of the control group, which we used as a proxy for the severity of the disease.

\section{Methods}

We included controlled trials that compared the length of mechanical ventilation between vitamin $C$ and control groups. We included trials in which the administration of vitamin $\mathrm{C}$ was the only difference between the study groups; trials that administered other therapies as well as vitamin $C$ were included only if the other therapies were the same for both trial groups. We did not limit our search to randomized trials and did not require placebo control. We included all doses and all durations of vitamin $\mathrm{C}$ administration.

We searched MEDLINE, Scopus, and the Cochrane Register on 13 Nov 2019 with the search phrases described in Fig. 1 . We had previously searched the same databases for trials on vitamin $\mathrm{C}$ and ICU length of stay on 20 Jan 2019 [1]; from that search, we found trials that were not well indexed and so not identified in our new search specifically for trials on vitamin $C$ and mechanical ventilation. Finally, we perused the reference lists of the selected trials and relevant reviews, from which we discovered two more trials. We identified nine trials satisfying our selection criteria [11-19]. We did not include two further trials that reported "ventilator-free days" since we were unable to convert this to our outcome of interest, "duration of mechanical ventilation" [20, 21].

Tanaka et al. administered vitamin $\mathrm{C}$ continuously with a dosage of $66 \mathrm{mg} / \mathrm{kg} / \mathrm{h}$ for the first $24 \mathrm{~h}$ only, with the reported mean weight of patients being $57 \mathrm{~kg}$ [17]. Thus, we

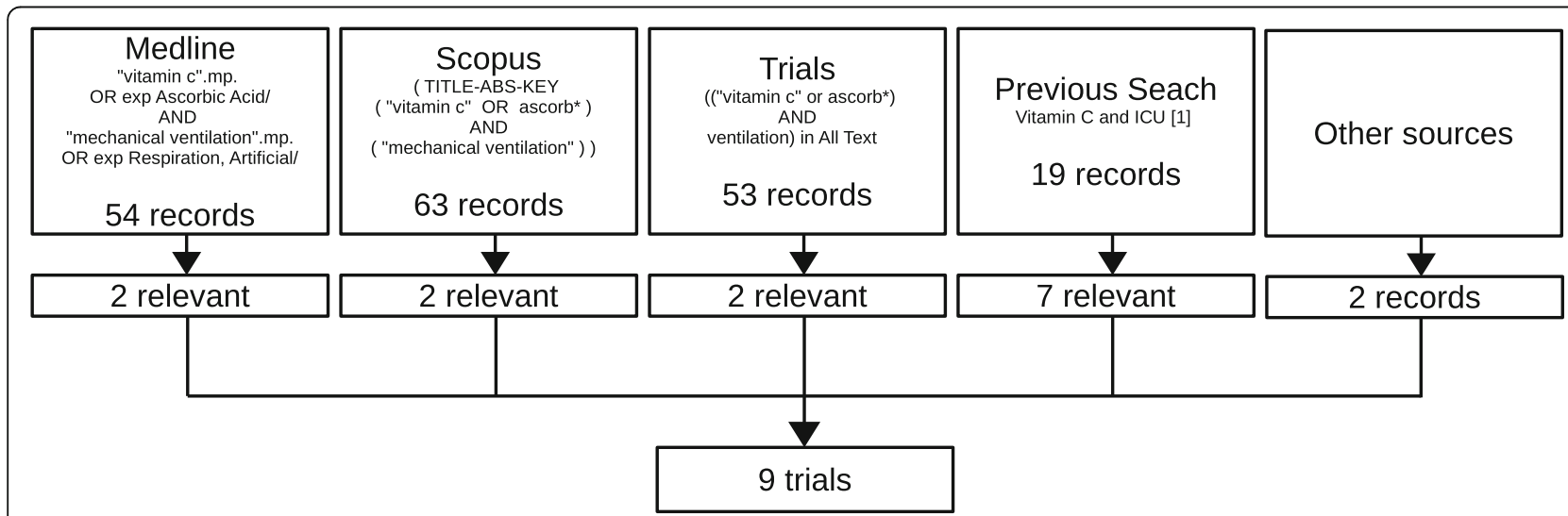

Fig. 1 Flow diagram showing the search terms. The searches were carried out on 13 Nov 2019. The searches identified nine trials that we included in our systematic review analysis [11-19] and eight of them were included in our meta-analysis [11-18] 
calculated that the average dose was $90 \mathrm{~g} /$ day in the Tanaka trial. Zabet et al. administered $25 \mathrm{mg} / \mathrm{kg}$ every $6 \mathrm{~h}$, but the mean weight was not reported [18]. Assuming a mean weight of $60 \mathrm{~kg}$, we estimated that the average dose was $6 \mathrm{~g} /$ day in the Zabet trial. We use these estimates in our text.

The outcome in this analysis is the length of mechanical ventilation, which we analyzed on the relative scale. The relative scale is usually more informative than the absolute scale for the analysis of treatment effects on continuous outcomes, in particular, for the analysis of duration data $[1,22-24]$. We used the ratio of means (RoM) to estimate the effect of vitamin $\mathrm{C}$, and the Taylor series-based approach to calculate the $\log (\operatorname{RoM})$ [22].

We pooled the selected trials with the metagen function of the meta package of the R statistical software [25-27], using the inverse variance, fixed effect options. For metaregression, we used the metareg function of the meta package. We used the $\chi^{2}$ test and the $I^{2}$ statistic to assess statistical heterogeneity among the trials in the metaanalysis [28]. Values of $I^{2}$ range from $0 \%$ to $100 \%$. A value close to $0 \%$ indicates very low-level heterogeneity. A value of more than approximately $50 \%$ indicates moderate heterogeneity, and a value over $75 \%$ indicates highlevel heterogeneity. Our calculations are described in Additional files 1 and 2.

\section{Results}

\section{Description of the included trials}

Nine controlled trials have reported on vitamin C administration and the length of mechanical ventilation (Table 1; see Additional file 1: Table S1 for further details of the trials). The flow diagram of our search is shown in Fig. 1.

The total number of patients was 975 , with 810 patients in six cardiac surgery trials, 128 patients in two sepsis trials, and 37 patients in one trial with burns patients (Table 1). Vitamin $\mathrm{C}$ was administered orally in four trials and intravenously in five trials. The Tanaka [17] trial administered $90 \mathrm{~g} /$ day, whereas the other seven trials administered from 1 to $6 \mathrm{~g} /$ day. Safaei et al. [15] and Tanaka et al. [17] administered vitamin $C$ on a single day only, six trials administered for $2-5$ days [11-13, $16,18,19]$, and one administered "until ICU discharge" for septic shock patients [14]. There is a 250 -fold variation in the average length of mechanical ventilation in the untreated groups from $2 \mathrm{~h}$ [16] to $511 \mathrm{~h}$ [17], which reflects great variation in the severity of the baseline medical condition (Table 1).

Six trials were randomized $[11-13,15,18,19]$, two used alternative allocation [14, 17], and one did not describe the allocation method [16]. The reported baseline variables for the treatment groups were balanced in all trials (Additional file 1: Table S1). The risk of bias assessment of the trials is shown in Fig. 2. Four trials used an explicit placebo [11, 16, 18, 19]. The trial by Sadeghpour et al. [19] had a high dropout rate, with 500 participants recruited, but results were reported for just 290 participants [1]. We did not include this trial in our statistical models, but the results are presented separately.

\section{Results of the included trials}

In our standard meta-analyses, we pooled the results of the trials on the relative scale, calculating the ratio of means

Table 1 Description of the included trials

\begin{tabular}{|c|c|c|c|c|c|c|c|c|c|}
\hline \multirow[t]{3}{*}{ Trial [ref.] } & \multirow[t]{3}{*}{$N$} & \multirow[t]{3}{*}{ Setting } & \multicolumn{2}{|c|}{ Vitamin C } & \multicolumn{4}{|c|}{ Length of mechanical ventilation (hours) } & \multirow[t]{3}{*}{ RoM } \\
\hline & & & \multirow[t]{2}{*}{ Route } & \multirow[t]{2}{*}{ Dose (g/day) } & \multicolumn{2}{|c|}{ Vitamin C } & \multicolumn{2}{|c|}{ Control } & \\
\hline & & & & & Mean & SD & Mean & SD & \\
\hline Bjordahl et al. [11] & 185 & Cardiac & po & 2 & 28.8 & 19.2 & 33.6 & 24.0 & 0.86 \\
\hline Amini et al. [12] & 137 & Cardiac & po & 3 & 7.3 & 6.0 & 6.7 & 4.3 & 1.10 \\
\hline Dehghani et al .[13] & 100 & Cardiac & po & 1 & 13.4 & 2.0 & 15.4 & 14.3 & 0.87 \\
\hline Habib et al. [14] & 100 & Sepsis & iv & 6 & 110 & 50 & 189 & 72 & 0.58 \\
\hline Safaei et al. [15] & 58 & Cardiac & iv & 2 & 15.1 & 5.39 & 22.9 & 20.46 & 0.66 \\
\hline Ebade et al. [16] & 40 & Cardiac & iv & 3 & 2.04 & 0.35 & 1.99 & 0.31 & 1.02 \\
\hline Tanaka et al. [17] & 37 & Burns & iv & $90^{*}$ & 290 & 211 & 511 & 374 & 0.57 \\
\hline Zabet et al. [18] & 28 & Sepsis & iv & $6^{*}$ & 36.6 & 16.1 & 46.8 & 10.1 & 0.78 \\
\hline Sadeghpour et al. [19]** & 290 & Cardiac & po & 1 & 11.8 & 3.9 & 14.1 & 9.5 & 0.84 \\
\hline
\end{tabular}

The trials are listed by the number of patients $(N)$. The mean age in the trials ranged from 42 to 64 years, with a median of 60 years. The proportion of males varied from $58 \%$ to $75 \%$. Five trials were carried out in Iran [12, 13, 15, 18, 19], two in Egypt [14, 16], one in the USA [11], and one in Japan [17]. For detailed descriptions of the trials, see Additional file 1: Table S1. The Amini trial [12] results are modified as described previously [1]

*Estimated vitamin $C$ dose, see the "Methods" section

**Sadeghpour et al. [19] recruited 500 participants but reported the results for just 290 participants [1]. Because of the high dropout rate (42\%), we did not include this trial in our calculations, but we overlay the findings in Fig. 4

iv intravenous, po per oral, RoM ratio of means [22]: e.g., for the Bjordahl trial [11], $R o M=0.86$, based on $28.8 / 33.6$, and RoM $=0.86$ indicates that ventilation time in the vitamin $C$ group was $14 \%$ shorter than in the placebo group 


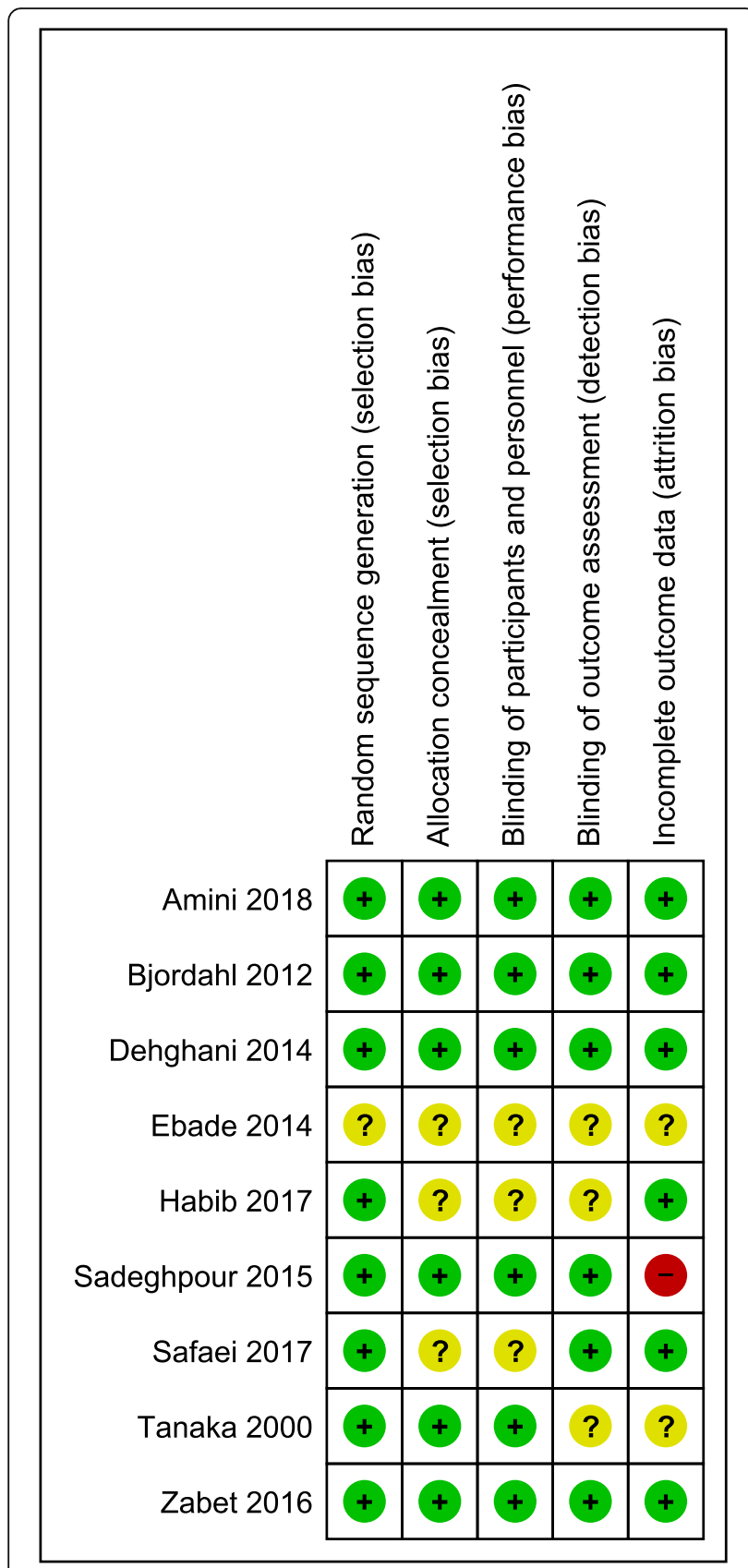

Fig. 2 Risk of bias summary. Review authors' judgments about each risk of bias item for each included trial. A green plus sign (+) indicates that there is no substantial concern for bias in the particular quality item. A question mark (?) indicates that conclusions are unable to be drawn regarding potential bias. A red minus sign (-) indicates that there is an explicit concern regarding bias. In the Sadeghpour trial, the dropout rate was very high (42\%), justifying the minus sign [1]. The reference numbers to the trials are shown in Table 1

(RoM) [22]. For example, in the Bjordahl trial [11], the length of mechanical ventilation was $28.8 \mathrm{~h}$ in the vitamin $\mathrm{C}$ group and $33.6 \mathrm{~h}$ in the placebo group, which corresponds to RoM $=0.86(28.8 / 33.6)$ (Table 1). This represents a $14 \%$ shorter ventilation time in the vitamin $\mathrm{C}$ group.
Over the eight included trials with 685 patients in total, vitamin $C$ shortened the length of mechanical ventilation on average by $14 \%\left(P=10^{-5}\right)$ (Fig. 3). However, there was highly significant heterogeneity in the vitamin $C$ effect between the trials with $I^{2}=83 \%\left(P=4.8 \times 10^{-7}\right)$. This indicates that the calculated average effect of $14 \%$ is not consistent over all the included trials.

In a meta-regression analysis, we found that the heterogeneity between the trials was explained by the length of mechanical ventilation in the untreated control group (Fig. 4). The evidence for modification of the vitamin C effect by the untreated ventilation time was very strong $\left(P=10^{-7}\right)$. There is little residual heterogeneity around the regression line with $I^{2}=12 \%(P=0.3)$, which indicates that the meta-regression in Fig. 4 much better captures the findings of the trials compared with the standard meta-analysis shown in Fig. 3. The confidence intervals of all included trials are consistent with the regression line in Fig. 4. The Habib [14] trial contributed considerable weight to the effect of vitamin $\mathrm{C}$ in Fig. 4. However, even if both the Habib [14] and Tanaka [17] trials are excluded, there is strong evidence from the six remaining trials that the effect of vitamin $\mathrm{C}$ is modified by the ventilation time in the untreated control group $(P=0.004)$ (see Additional file 1$)$.

Figure 4 indicates that no meaningful benefit from vitamin $\mathrm{C}$ is expected for patients whose ventilation time is shorter than $10 \mathrm{~h}$. On the other hand, the regression line in Fig. 4 predicts that for patients ventilated for 100 $\mathrm{h}$, vitamin $\mathrm{C}$ reduces the ventilation time on average by $31 \%(\mathrm{RoM}=0.69)$. Three trials administered vitamin $\mathrm{C}$ orally and five intravenously, but both methods are consistent with the single regression line in Fig. 4.

Tanaka et al. [17] used by far the highest dose of vita$\min \mathrm{C}, 90 \mathrm{~g} /$ day. Figure 4 indicates that the substantial benefit observed in that trial may be explained by the particularly sick patients with burns requiring very long ventilation, rather than by the very high vitamin $C$ dose. We found that vitamin $C$ shortened the length of ventilation on average by $25 \%\left(P=10^{-10}\right)$ when the Tanaka trial was excluded and the analysis was restricted to the five trials with dosage from 1 to $6 \mathrm{~g} /$ day for patients ventilated for over $10 \mathrm{~h}[11,13-15,18]$.

The Sadeghpour trial [19] is not included in our statistical models because of the high dropout rate, but the results are shown in Fig. 4 by the dashed line and they are consistent with the findings of the other trials.

Secondary analysis of vitamin C and E combination trials Our meta-regression analysis above was restricted to studies in which vitamin $\mathrm{C}$ was administered as the only difference between the study groups. We did not carry out a systematic search for trials on the combination of vitamins $C$ and $E$, but in our search for 


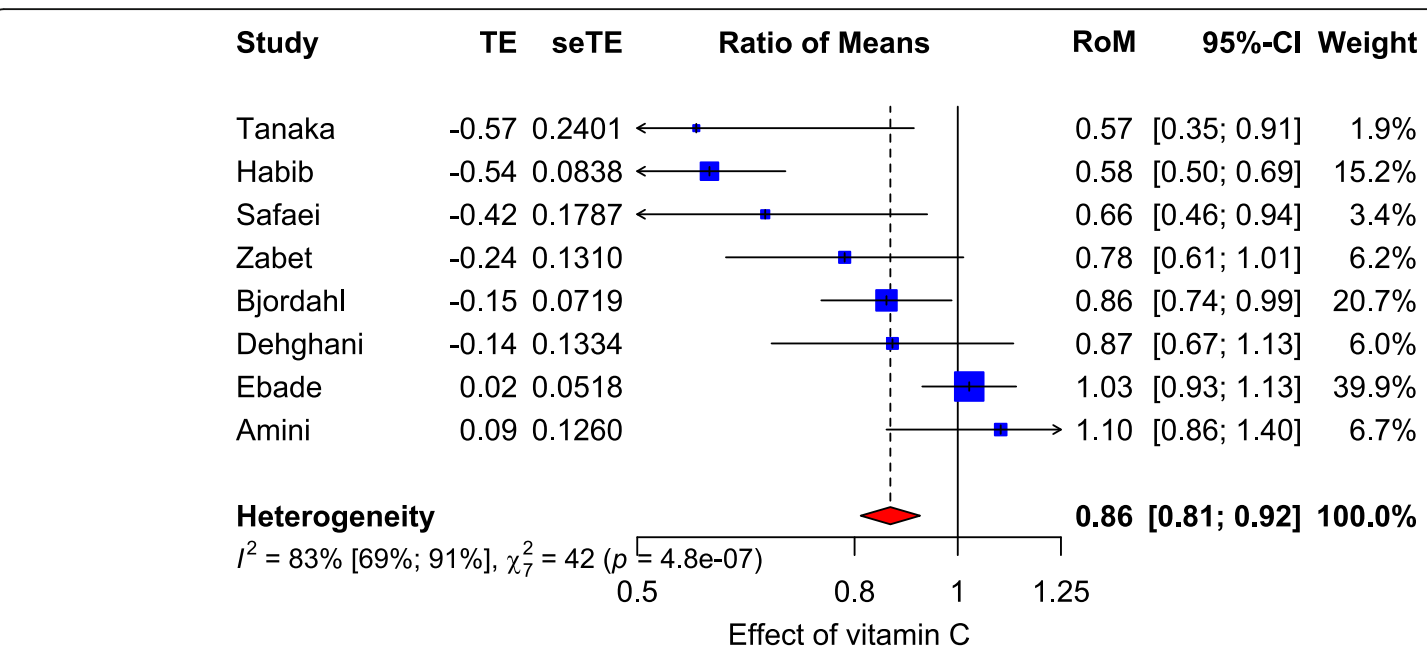

Fig. 3 Effect of vitamin C on the duration of ventilation. The horizontal lines indicate the $95 \% \mathrm{Cl}$ for the vitamin $\mathrm{C}$ effect and the blue squares in the middle of the horizontal lines indicate the point estimate of the effect in the particular trial. The red diamond shape indicates the pooled effect and its $95 \% \mathrm{Cl}$. The Sadeghpour trial [19] is not included in the meta-analysis, since the dropout rate was high (42\%) [1]. RoM ratio of means [22]

the vitamin $\mathrm{C}$ trials, we found three trials that administered vitamins $\mathrm{C}$ and $\mathrm{E}$ together to critically ill patients [29-31]. Given that our search for vitamin C also identifies any combinations of vitamins $\mathrm{C}$ and $\mathrm{E}$, it is unlikely that there are many more combination trials. As a secondary analysis, we compared the findings of the three vitamin $\mathrm{C}$ and $\mathrm{E}$ trials with our meta-regression model based on the eight trials using vitamin $\mathrm{C}$ alone (Fig. 5).
Nathens et al. administered $1 \mathrm{~g} /$ day vitamin $\mathrm{C}$ intravenously and $1000 \mathrm{IU} /$ day vitamin $E$ enterally [29]. The duration of mechanical ventilation in the control group was $110 \mathrm{~h}$, for which our model predicts a $32 \%$ decrease in the vitamin $\mathrm{C}$ group. The observed decrease in the vitamins C and E group was 20\% (95\% CI 13\% to 26\%).

Crimi et al. administered $0.5 \mathrm{~g} /$ day vitamin $\mathrm{C}$ and 400 IU/day vitamin E enterally [30]. Ventilation time in the control group was $213 \mathrm{~h}$, for which our model predicts a

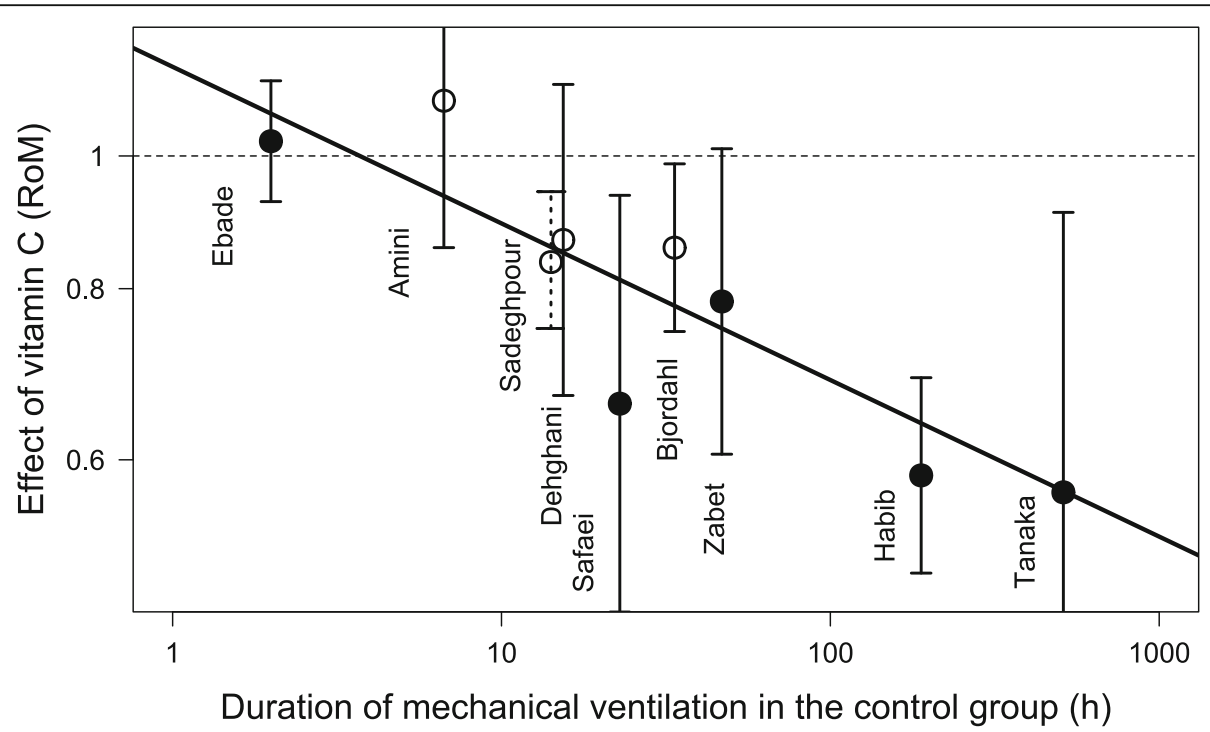

Fig. 4 Effect of vitamin $C$ on the duration of ventilation by the duration of ventilation in the control group. The horizontal dashed line indicates the null effect. The diagonal line shows the meta-regression line for the eight trials, with $P=10^{-7}$ for the test that the slope is not null. Vitamin $C$ was administered orally (open circles) or intravenously (filled circles). The regression line follows the formula $\ln ($ RoM $)=0.150-0.263 \times \log _{10}($ length of ventilation). For example, for a ventilation time of $100 \mathrm{~h}\left(\log _{10}[100]=2\right)$, the formula gives $\ln (\mathrm{RoM})=-0.377$, and predicts a vitamin $\mathrm{C}$ effect of RoM $=0.69$, i.e., a $31 \%$ shorter ventilation time. The Sadeghpour trial [19] is not included in the statistical model, since the dropout rate was high; however, it is overlaid here for information. For calculations, see Additional file 2. RoM ratio of means [22] 


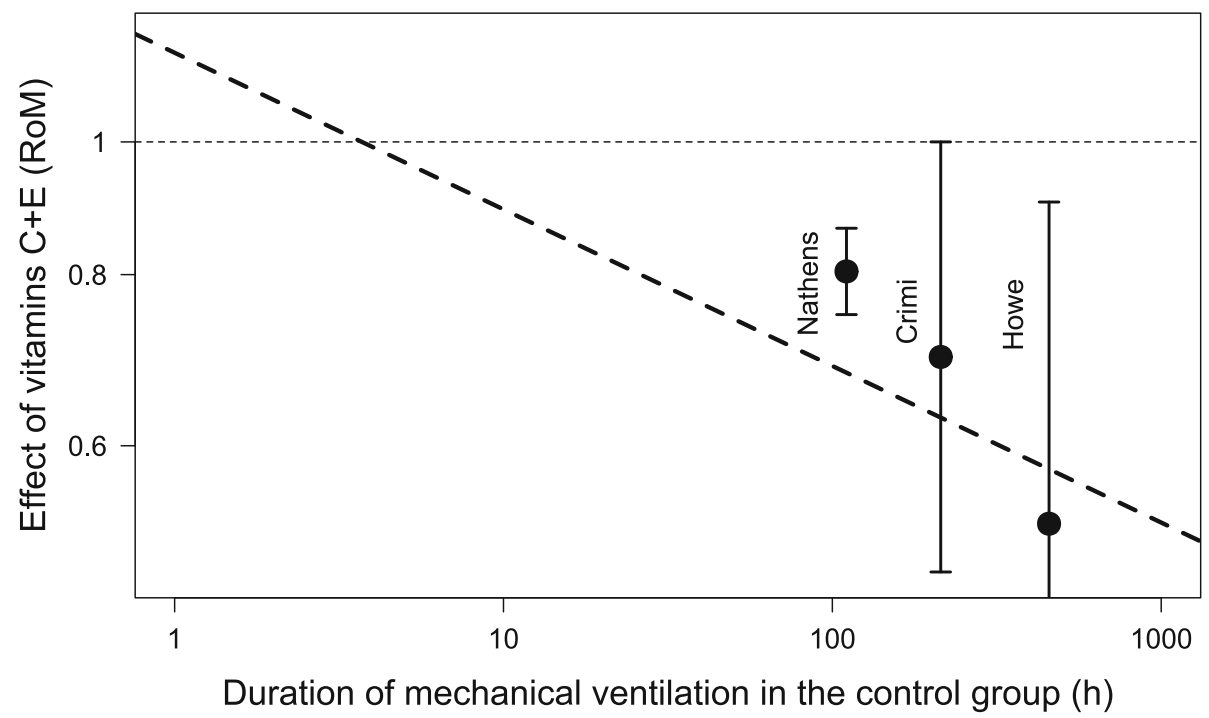

Fig. 5 Effect of the combination of vitamins $C$ and $E$ on the duration of ventilation by the duration of ventilation in the control group. The diagonal line shows the meta-regression line based on the vitamin $C$ alone trials from Fig. 4 . The horizontal dashed line indicates the null effect. The results of the three trials [29-31] and their 95\% Cls are shown. For calculations, see Additional file 2. RoM ratio of means [22]

$37 \%$ decrease in the vitamin $\mathrm{C}$ group. The observed decrease was $30 \%$ (95\% CI $0 \%$ to $61 \%)$.

Howe et al. administered $1 \mathrm{~g} /$ day vitamin $\mathrm{C}$ and 1000 IU/day vitamin E enterally [31]. Ventilation time in the control group was $456 \mathrm{~h}$, and our model predicts a $42 \%$ decrease in the vitamin $\mathrm{C}$ group. The observed decrease was $47 \%$ (95\% CI $7 \%$ to $87 \%$ ). In all three vitamin C and $\mathrm{E}$ trials, the observed effect of treatment was quite close to the effect predicted by the trials using only vitamin C (Fig. 5; see Additional files 1 and 2 for the calculations).

\section{Discussion}

There is significant variation in the severity of disease in patients who are mechanically ventilated. One measure of severity is the mechanical ventilation time required by the patient, which we used as a proxy for severity. In this study, we found that the duration of ventilation in the untreated control group explained most of the variation in the reported effects of vitamin $\mathrm{C}$ on the mechanical ventilation time. In the standard meta-analysis, there is high-level heterogeneity with $I^{2}=83 \%$ (Fig. 3), whereas in the meta-regression of the vitamin $\mathrm{C}$ effect by the control group duration of ventilation, the residual heterogeneity is small with $I^{2}=12 \%$ (Fig. 4).

Some of the included trials examined elective surgical patients. These patients are not usually critically ill; however, as a result of their surgery, they are routinely ventilated in the ICU for a period of time. In the metaregression, such patients are located on the left-hand side of Fig. 4 which means that the analysis takes into account the low level of illness severity. In contrast, the inclusion of patients with less severe disease in the standard meta-analysis decreases the average effect of vitamin $\mathrm{C}$, so that the greater effect on the sicker patients is masked (Fig. 3).

The substantial benefit observed in the Tanaka [17] trial seems to be explained by the particularly long mechanical ventilation in the untreated control patients (which reflects the greater illness severity), rather than the particularly high vitamin $C$ dosage of $90 \mathrm{~g} /$ day in that trial. All the other trials used $6 \mathrm{~g} /$ day or less, but there is no evidence that the benefit was less than in the Tanaka trial when taking into account the ventilation time in the untreated control group (Fig. 4). There are a few reports of deaths caused by intravenous vitamin $\mathrm{C}$ in doses of 80 to $224 \mathrm{~g} /$ day $[32,33]$. Therefore, the interpretation that the benefit in the Tanaka trial may be caused by the type of patients and not by the very high vitamin $\mathrm{C}$ dose is important for planning further trials.

Our previous analysis of the length of ICU stay also found that the effect of vitamin $\mathrm{C}$ appeared greater for the sicker patients. The length of ICU stay was reduced by $10.1 \%(P=0.0001)$ in patients who required an ICU stay of 3 days or longer, but by just $5.7 \%(P=0.03)$ in those who needed only $1-2$ days in the ICU [1].

There are also other findings that are consistent with vitamin $\mathrm{C}$ having a greater effect on patients with more severe medical conditions. A meta-analysis of vitamin C effect on exercise-induced bronchoconstriction found that vitamin $\mathrm{C}$ halved $\mathrm{FEV}_{1}$ decline caused by exercise [34]. The constant relative effect indicates that the absolute effect was greatest for patients who had the greatest bronchoconstriction in the exercise test. Finally, a trial 
with common cold patients indicated that the bronchodilatory effect of vitamin $\mathrm{C}$ was most beneficial for those with the greatest bronchial hypersensitivity to histamine $[35,36]$.

There is much evidence indicating that vitamins $C$ and $E$ have an interaction in vitro and in vivo [37-41], and three trials have examined the effect of the combination of vitamins $C$ and $E$ on the duration of mechanical ventilation [29-31]. The reported effects from the three trials are largely consistent with the meta-regression model based on the eight trials using vitamin $\mathrm{C}$ alone (Fig. 5), though the confidence interval of the Nathens et al. trial does not cross the regression line. Thus, the statistically significant benefit observed in each of these three trials might be explained by the long ventilation time in the control groups, indicating greater severity of illness in the patients, rather than by the addition of vitamin $E$ to the intervention. To test the possible additional benefit of vitamin $\mathrm{E}$ over vitamin $\mathrm{C}$ would require $2 \times 2$ factorial trials.

Although our meta-regression analysis by the ventilation time in the control group explains the heterogeneity in the published trials, it seems evident that other variables influence the effects of vitamin C. For example, there are indications that treatment effects can differ between less and more developed countries. Panagiotou et al. identified several studies that reported greater treatment effects in less developed countries than in more developed countries [42]. Although methodological variations may explain some of the differences, there can also be genuine treatment differences between substantially different cultures, since wealth is strongly correlated with life-style factors including nutrition and with differences in hospital treatments. Previously, vitamin $C$ was found to prevent post-operative atrial fibrillation in non-US trials, but not in US-based trials [43], which may also indicate that the effects of vitamin $\mathrm{C}$ can depend on cultural context. Thus, although the fit of the meta-regression line in Fig. 4 is good, the findings should not be extrapolated directly to other contexts.

Two recent meta-analyses concluded that vitamin $\mathrm{C}$ is not beneficial for critically ill patients [44, 45], whereas a third concluded that vitamin $\mathrm{C}$ was beneficial for sepsis patients [46]. However, all three meta-analyses included studies that administered vitamin $\mathrm{C}$ in combination with numerous other substances, such as vitamins $\mathrm{A}, \mathrm{B}$, and E, selenium, and zinc [47-49]. Such trials do not test the specific effect of vitamin $C$. The other substances can have negative or positive effects, and they can also modify the effect of vitamin $\mathrm{C}$. The three meta-analyses also had statistical shortcomings [47-49]. Our current metaanalysis was restricted to trials that tested vitamin $\mathrm{C}$ alone. A fourth recent meta-analysis concluded that vitamin $\mathrm{C}$ shortens ventilation time in cardiac surgery patients [50]; however, the study was shown to contain several substantial statistical errors [51].

In systematic reviews, one potential concern is publication bias, in that negative trials may remain unpublished. However, publication bias cannot realistically generate the close association shown in Fig. 4. To explain this association by publication bias would require that positive studies with less ill patients remain unpublished, and negative studies with severely ill patients also remain unpublished. Five trials did not use an explicit placebo [12-15, 17], but we do not consider that the lack of placebo undermines the validity of those trials, since ICU patients receive numerous treatments and it is unlikely that one additional tablet or infusion would cause a substantial placebo effect for ventilated patients. The lack of a placebo may cause bias in research on subjective outcomes, but less so on objective outcomes [52]. Thus, it is unlikely to bias studies with outcomes such as the duration of mechanical ventilation.

\section{Conclusions}

It may not be worthwhile to carry out further research on the effects of vitamin $C$ on mechanical ventilation for patient groups that require on average less than $10 \mathrm{~h}$ of ventilation. The level of sickness severity should be taken into account in future studies, for example, by evaluating prognostic scores at the start of the trial. Our analysis did not find differences between oral and intravenous vitamin $\mathrm{C}$, but oral administration is rarely an option for the sickest patients, for whom the effects of vitamin $\mathrm{C}$ appear greatest. Our analysis is not informative about the optimal dosage of vitamin C. Future trials should directly compare different dosage levels.

\section{Supplementary information}

Supplementary information accompanies this paper at https://doi.org/10. 1186/s40560-020-0432-y.

Additional file 1 Calculations; Table S1. Detailed description of the included trials.

Additional file 2. The data set used in this analysis.

\section{Authors' contributions}

$\mathrm{HH}$ and EC planned the study and searched the literature and selected the trials to be included. $\mathrm{HH}$ entered the data into a spreadsheet and carried out the statistical analysis. EC checked that the entered data were consistent with original reports. $\mathrm{HH}$ wrote the draft manuscript and EC participated in the critical revision of the manuscript. Both authors read and approved the final manuscript.

\section{Funding}

No external funding

Availability of data and materials

Descriptions of the included trials, and the risk of bias assessment, and the analyzed data are available as Additional files 1 and 2 . 


\section{Ethics approval and consent to participate}

Not applicable; this is a meta-analysis of studies already published.

\section{Consent for publication}

Not applicable

\section{Competing interests}

The authors declare that they have no competing interests.

\section{Author details}

'Department of Public Health, University of Helsinki, POB 41, Fl-00014

Helsinki, Finland. 'University of Sydney, Sydney, Australia.

\section{Received: 1 December 2019 Accepted: 17 January 2020}

\section{Published online: 07 February 2020}

\section{References}

1. Hemilä H, Chalker E. Vitamin C can shorten the length of stay in the ICU: a meta-analysis. Nutrients. 2019;11:708. https://doi.org/10.3390/nu11040708.

2. Long CL, Maull Kl, Krishnan RS, Laws HL, Geiger JW, Borghesi L, Franks W, Lawson TC, Sauberlich HE. Ascorbic acid dynamics in the seriously ill and injured. J Surg Res. 2003;109:144-8. https://doi.org/10.1016/S00224804(02)00083-5.

3. Rümelin A, Jaehde U, Kerz T, Roth W, Krämer M, Fauth U. Early postoperative substitution procedure of the antioxidant ascorbic acid. J Nutr Biochem. 2005:16:104-8. https://doi.org/10.1016/j.jnutbio.2004.10.005.

4. Rümelin A, Humbert T, Lühker O, Drescher A, Fauth U. Metabolic clearance of the antioxidant ascorbic acid in surgical patients. J Surg Res. 2005;129:4651. https://doi.org/10.1016/j.jss.2005.03.017.

5. De Grooth HJ, Manubulu-Choo WP, Zandvliet AS, Spoelstra-de Man AME, Girbes AR, Swart EL, Oudemans-van Straaten HM. Vitamin C pharmacokinetics in critically ill patients: a randomized trial of four iv regimens. Chest. 2018;153:1368-77. https://doi.org/10.1016/j.chest.2018. 02.025 .

6. Schorah CJ, Downing C, Piripitsi A, Gallivan L, Al-Hazaa AH, Sanderson MJ, Bodenham A. Total vitamin C, ascorbic acid, and dehydroascorbic acid concentrations in plasma of critically ill patients. Am J Clin Nutr. 1996;63: 760-7. https://doi.org/10.1093/ajcn/63.5.760.

7. Galley HF, Davies MJ, Webster NR. Ascorbyl radical formation in patients with sepsis: effect of ascorbate loading. Free Radic Biol Med. 1996;20:13943. https://doi.org/10.1016/0891-5849(95)02022-5.

8. Evans-Olders R, Eintracht S, Hoffer LJ. Metabolic origin of hypovitaminosis C in acutely hospitalized patients. Nutrition. 2010;26:1070-4. https://doi.org/10. 1016/j.nut.2009.08.015

9. Rodemeister S, Duquesne M, Adolph M, Nohr D, Biesalski HK, Unertl K. Massive and long-lasting decrease in vitamin C plasma levels as a consequence of extracorporeal circulation. Nutrition. 2014;30:673-8. https://doi.org/10.1016/j.nut.2013.10.026.

10. Carr AC, Rosengrave PC, Bayer S, Chambers S, Mehrtens J, Shaw GM Hypovitaminosis C and vitamin C deficiency in critically ill patients despite recommended enteral and parenteral intakes. Crit Care. 2017;21:300. https:// doi.org/10.1186/s13054-017-1891-y.

11. Bjordahl PM, Helmer SD, Gosnell DJ, Wemmer GE, O'Hara WW, Milfeld DJ. Perioperative supplementation with ascorbic acid does not prevent atrial fibrillation in coronary artery bypass graft patients. Am J Surg. 2012;204:8627. https://doi.org/10.1016/j.amjsurg.2012.03.012

12. Amini S, Robabi HN, Tashnizi MA, Vakili V. Selenium, vitamin C and Nacetylcysteine do not reduce the risk of acute kidney injury after off-pump CABG: a randomized clinical trial. Braz J Cardiovasc Surg. 2018:33:129-34. https://doi.org/10.21470/1678-9741-2017-0071

13. Dehghani MR, Madjidi N, Rahmani A, Asgari B, Rezaei Y. Effect of oral vitamin $C$ on atrial fibrillation development after isolated coronary artery bypass grafting surgery: a prospective randomized clinical trial. Cardiol J. 2014;21:492-9. https://doi.org/10.5603/CJ.a2013.0154

14. Habib TN, Ahmed I. Early adjuvant intravenous vitamin C treatment in septic shock may resolve the vasopressor dependence. Int J Microbiol Adv Immunol. 2017;5:77-81. https://doi.org/10.19070/2329-9967-1700015.

15. Safaei N, Babaei $H$, Azarfarin $R$, Jodati AR, Yaghoubi A, Sheikhalizadeh MA. Comparative effect of grape seed extract (vitis vinifera) and ascorbic acid in oxidative stress induced by on-pump coronary artery bypass surgery. Ann Cardiac Anaesth 2017;20:45-51. https://doi.org/10.4103/0971-9784.197834.
16. Ebade A, Taha WS, Saleh RH, Fawzy A. Ascorbic acid versus magnesium for the prevention of atrial fibrillation after coronary artery bypass grafting surgery. Egypt J Cardiothorac Anesth. 2014;8:59-65. https://doi.org/10.4103/ 1687-9090.143259.

17. Tanaka H, Matsuda T, Miyagantani Y, Yukioka T, Matsuda H, Shimazaki S. Reduction of resuscitation fluid volumes in severely burned patients using ascorbic acid administration: a randomized prospective study. Arch Surg. 2000;135:326-31. https://doi.org/10.1001/archsurg.135.3.326.

18. Zabet MH, Mohammadi M, Ramezani M, Khalili $\mathrm{H}$. Effect of high-dose ascorbic acid on vasopressor's requirement in septic shock. J Res Pharm Pract. 2016:5:94-100. https://doi.org/10.4103/2279-042X.179569.

19. Sadeghpour A, Alizadehasl A, Kyavar M, Sadeghi T, Moludi J, Gholizadeh F, Totonchi Z, Ghadrdoost B. Impact of vitamin C supplementation on postcardiac surgery ICU and hospital length of stay. Anesth Pain Med. 2015;5: e25337. https://doi.org/10.5812/aapm.25337.

20. Fowler AA 3rd, Syed AA, Knowlson S, Sculthorpe R, Farthing D, DeWilde C, Farthing CA, Larus TL, Martin E, Brophy DF, Gupta S, Medical Respiratory Intensive Care Unit Nursing, Fisher BJ, Natarajan R. Phase I safety trial of intravenous ascorbic acid in patients with severe sepsis. J Transl Med. 2014; 12:32. https://doi.org/10.1186/1479-5876-12-32.

21. Fowler AA 3rd, Truwit JD, Hite RD, Morris PE, DeWilde C, Priday A, Fisher B, Thacker LR 2nd, Natarajan R, Brophy DF, Sculthorpe R, Nanchal R, Syed A, Sturgill J, Martin GS, Sevransky J, Kashiouris M, Hamman S, Egan KF, Hastings A, Spencer W, Tench S, Mehkri O, Bindas J, Duggal A, Graf J, Zellner S, Yanny L, McPolin C, Hollrith T, Kramer D, Ojielo C, Damm T, Cassity E, Wieliczko A, Halquist M. Effect of vitamin C infusion on organ failure and biomarkers of inflammation and vascular injury in patients with sepsis and severe acute respiratory failure: the CITRIS-ALI randomized clinical trial. JAMA. 2019;322:1261-70. https://doi.org/10.1001/jama.2019.11825.

22. Friedrich JO, Adhikari NK, Beyene J. Ratio of means for analyzing continuous outcomes in meta-analysis performed as well as mean difference methods. J Clin Epidemiol. 2011;64:556-64. https://doi.org/10.1016/j.jclinepi.2010.09.016.

23. Hemilä H. Many continuous variables such as the duration of the common cold should be analyzed using the relative scale. J Clin Epidemiol. 2016;78: 128-9. https://doi.org/10.1016/j.jclinepi.2016.03.020.

24. Hemilä H. Duration of the common cold and similar continuous outcomes should be analyzed on the relative scale: a case study of two zinc lozenge trials. BMC Med Res Methodol. 2017;17:82. https:/doi.org/10.1186/s12874-017-0356-y.

25. R Core Team. R Project for Statistical Computing, (2019). https://www.rproject.org Accessed 5 Jan 2020.

26. Schwarzer G. meta: an R package for meta-analysis. R News. 2009;7:40-5 https://cran.r-project.org/doc/Rnews/Rnews_2007-3.pdf Accessed 5 Jan 2020.

27. Schwarzer G, Carpenter JR, Rucker G. Meta-analysis with R. London: Springer. https://doi.org/10.1007/978-3-319-21416-0.

28. Higgins JPT, Thompson SG, Deeks JJ, Altman DG. Measuring inconsistency in meta-analysis. BMJ. 2003;327:557-60. https://doi.org/10.1136/bmj.327. 7414.557.

29. Nathens AB, Neff MJ, Jurkovich GJ, Klotz P, Farver K, Ruzinski JT, Radella F, Garcia I, Maier RV. Randomized, prospective trial of antioxidant supplementation in critically ill surgical patients. Ann Surg. 2002;236:814-22. https://doi.org/10.1097/00000658-200212000-00014.

30. Crimi E, Liguori A, Condorelli M, Cioffi M, Astuto M, Bontempo P, Pignalosa O, Vietri MT, Molinari AM, Sica V, Della Corte F, Napoli C. The beneficial effects of antioxidant supplementation in enteral feeding in critically ill patients: a prospective, randomized, double-blind, placebo-controlled trial. Anesth Analg. 2004;99:857-63. https://doi.org/10.1213/01.ANE.0000133144. 60584.F6.

31. Howe KP, Clochesy JM, Goldstein LS, Owen H. Mechanical ventilation antioxidant trial. Am J Crit Care. 2015;24:440-5. https://www.ncbi.nlm.nih. gov/pubmed/26330437

32. Campbell GD Jr, Steinberg MH, Bower JD. Ascorbic acid-induced hemolysis in G-6-PD deficiency. Ann Intern Med. 1975;82:810. https://doi.org/10.7326/ 0003-4819-82-6-810_1.

33. Buehner M, Pamplin J, Studer L, Hughes RL, King BT, Graybill JC, Chung KK. Oxalate nephropathy after continuous infusion of high-dose vitamin $\mathrm{C}$ as an adjunct to burn resuscitation. J Burn Care Res. 2016;37:e374-9. https://doi. org/10.1097/BCR.0000000000000233.

34. Hemilä H. Vitamin C may alleviate exercise-induced bronchoconstriction: a meta-analysis. BMJ Open 2013:3:e002416. doi: https://doi.org/10.1136/ bmjopen-2012-002416 
35. Bucca C, Rolla G, Arossa W, Caria E, Elia C, Nebiolo F, Baldi S. Effect of ascorbic acid on increased bronchial responsiveness during upper airway infection. Respiration. 1989;55:214-9. https://doi.org/10.1159/000195737.

36. Hemilä H. Vitamin C and common cold-induced asthma: a systematic review and statistical analysis. Allergy Asthma Clin Immunol. 2013;9:46. https://doi.org/10.1186/1710-1492-9-46.

37. Sharma MK, Buettner GR. Interaction of vitamin $C$ and vitamin $E$ during free radical stress in plasma: an ESR study. Free Rad Biol Med. 1993;15:649-53. https://doi.org/10.1016/0891-5849(93)90146-L.

38. Huang J, May JM. Ascorbic acid spares alpha-tocopherol and prevents lipid peroxidation in cultured H4llE liver cells. Mol Cell Biochem. 2003;247:171-6. https://doi.org/10.1023/a:1024167731074.

39. Hill KE, Montine TJ, Motley AK, Li X, May JM, Burk RF. Combined deficiency of vitamins $E$ and $C$ causes paralysis and death in Guinea pigs. Am J Clin Nutr. 2003:77:1484-8. https://doi.org/10.1093/ajcn/77.6.1484.

40. Bruno RS, Leonard SW, Atkinson J, Montine TJ, Ramakrishnan R, Bray TM Traber MG. Faster plasma vitamin E disappearance in smokers is normalized by vitamin C supplementation. Free Radic Biol Med. 2006;40:689-97. https://doi.org/10.1016/j.freeradbiomed.2005.10.051.

41. Hemilä H, Kaprio J. Modification of the effect of vitamin E supplementation on the mortality of male smokers by age and dietary vitamin C. Am J Epidemiol. 2009;169:946-53. https://doi.org/10.1093/aje/kwn413.

42. Panagiotou OA, Contopoulos-loannidis DG, loannidis JP. Comparative effect sizes in randomised trials from less developed and more developed countries: meta-epidemiological assessment. BMJ. 2013;346:f707. https://doi.org/10.1136/bmi.f707.

43. Hemilä H, Suonsyrjä T. Vitamin C for preventing atrial fibrillation in high risk patients: a systematic review and meta-analysis. BMC Cardiovasc Disord. 2017;17:49. https://doi.org/10.1186/s12872-017-0478-5.

44. Langlois PL, Manzanares W, Adhikari NKJ, Lamontagne F, Stoppe C, Hill A, Heyland DK. Vitamin C administration to the critically ill: a systematic review and meta-analysis. JPEN J Parenter Enteral Nutr. 2019;43:335-46. https://doi.org/10.1002/jpen.1471.

45. Putzu A, Daems AM, Lopez-Delgado JC, Giordano VF, Landoni G. The effect of vitamin C on clinical outcome in critically ill patients: a systematic review with meta-analysis of randomized controlled trials. Crit Care Med. 2019;47: 774-83. https://doi.org/10.1097/CCM.0000000000003700.

46. Li J. Evidence is stronger than you think: a meta-analysis of vitamin C use in patients with sepsis. Crit Care. 2018;22:258. https://doi.org/10.1186/s13054018-2191-X.

47. Hemilä H. Misleading meta-analysis on vitamin C and critically ill patients. PubPeer. https://pubpeer.com/publications/D661E94CBDF6C6A9C04 B8ACCD32DFC Accessed 5 Jan 2020.

48. Hemilä H. Statistical problems in a meta-analysis on vitamin $C$ and critically ill patients. PubPeer. https://pubpeer.com/publications/31E6DF677EC5A16 CFBD1908ADACD15\#1 Accessed 5 Jan 2020.

49. Hemilä H. Misleading meta-analysis on vitamin C for sepsis patients. PubPeer. https://pubpeer.com/publications/2D26F22CEA264D1B8491 0D89AD26D7 Accessed 5 Jan 2020.

50. Hill A. Clasen KC. Wendt S. Majoros ÁG. Stoppe C. Adhikari NKJ. Heyland DK Benstoem C. Effects of vitamin C on organ function in cardiac surgery patients: a systematic review and meta-analysis. Nutrients. 2019;11:2103. doi: https://doi.org/10.3390/nu1 1092103

51. Hemilä H, Chalker E. Vitamin C for cardiac surgery patients: several errors in a published meta-analysis. Comment on "Effects of Vitamin C on Organ Function in Cardiac Surgery Patients: A Systematic Review and MetaAnalysis. Nutrients 2019, 11, 2103" [Comment]. Nutrients. 2020 (in press). https://www.mv.helsinki.fi/home/hemila/hill. Accessed 22 Jan 2020.

52. Hrobjartsson A, Gøtzsche PC. Is the placebo powerless? An analysis of clinical trials comparing placebo with no treatment. N Engl J Med. 2001;344: 1594-602. https://doi.org/10.1056/NEJM200105243442106.

\section{Publisher's Note}

Springer Nature remains neutral with regard to jurisdictional claims in published maps and institutional affiliations.

\section{Ready to submit your research? Choose BMC and benefit from:}

- fast, convenient online submission

- thorough peer review by experienced researchers in your field

- rapid publication on acceptance

- support for research data, including large and complex data types

- gold Open Access which fosters wider collaboration and increased citations

- maximum visibility for your research: over $100 \mathrm{M}$ website views per year

At BMC, research is always in progress.

Learn more biomedcentral.com/submissions 